\title{
SPECIES OF WIDOW SPIDERS IN NORTHERN ARGENTINA \\ (LATRODECTUS: THERIDIIDAE)
}

\author{
By L. J. Pinter \\ Harvard University
}

\section{INTRODUCTION}

For more than fifty years there has been considerable controversy over the number of South American species in the genus Latrodectus. In a recent study Gerschman de Pikelin and Schiapelli (1965) reported that Latrodectus is represented by only two species, L. geometricus (Fabricius) and L. mactans C. L. Koch in Argentina. They opposed the findings of Abalos (1962), who suggested that at least five species of Latrodectus occur in Santiago del Estero, a northern province of Argentina. In addition to L. geometricus, Abalos proposed that four distinct species, temporarily designated No. I, No. 2, No. 3 and No. 4, comprise the mactans complex; whereas, Gerschman de Pikelin and Schiapelli believe that these four species ". . . . cannot be maintained because they are based only in the small differences in the form and size of their egg-sacs". Abalos and Baez (1967) supported the original findings of Abalos with additional ecological and morphological data. The present paper is concerned only with the four sympatric populations placed by Abalos and Baez into the "Latrodectus curacaviensis group" (No. I) and the "Latrodectus mactans group" (Nos. 2, 3 and 4).

I would like to acknowledge with sincere thanks the constant advice and encouragement by Dr. H. W. Levi of the Museum of Comparative Zoology and the loan of material by Dr. J. W. Abalos of the University of Córdoba, Córdoba, Argentina. The study was supported in part by Harvard University and by Public Health Service Research Grant AI-or 944 from the National Institute of Allergy and Infectious Diseases.

\section{METHODS}

In suggesting that the "curacaviensis-mactans" complex was comprised of four species, Abalos relied heavily upon field observations made in Santiago del Estero. On the other hand, Gerschman de Pikelin and Schiapelli relied mainly upon their studies of the morphological variations of specimens collected throughout Argentina and at least two neighboring countries. In order to minimize the problem of geographical variation within species, I limited my study to specimens collected in the small region sudied by Abalos. Furthermore, the study specimens were recently captured adult females which 
were preserved in a uniform manner. This was intended to reduce the problems resulting from ageing, e.g. differential fading and shrinking. Males were unavailable in sufficient numbers and were excluded from this study.

I would like to point out that Gerschman de Pikelin and Schiapelli noted variations in the size and color of the successive egg sacs from a single female. After examining the same egg sacs, Levi (pers. comm.) attributed the color variation to an unequal accumulation of dust on each of the egg sacs.

In a review of some North American Latrodectus, McCrone and Levi (1964) noted the distinct difference in the ventral abdominal patterns between $L$. mactans and $L$. variolus Walckenaer. This led me to study these familiar markings between the epigastric furrow and spinnerets. After examining several abdomens, I found that a few basic patterns were present on a majority of the specimens. These basic patterns and all variations of the basic patterns were sketched with the aid of a dissecting microscope equipped with an ocular grid. In this manner, the patterns from 266 specimens were compared.

In alcohol the red and yellow-brown pigments fade or wash out and as a result all pattern colors appear yellow or reddish-yellow. But there was a distinct difference between the color of the preservative of population No. 2 and the preservative of the other populations. The solutions from the vials containing No. 2 were tinted a deep orange while the preservative from the vials containing Nos. I, 3 and 4 was usually colorless or rarely tinted with yellow. In order to obtain reproducible spectra from each of the species, Dr. Abalos sent additional specimens of Nos. I, 2, and 3 which were preserved in alcohol. Additional specimens of No. 4 were unavailable. Upon receipt, each spider was washed in distilled water and $95 \%$ ethanol; the abdomen was divided along the mid-frontal plane; the internal organs and tissues of the ventral portion were excised; the exoskeletons were weighed and placed in separate vials containing equivalent proportions (weight/volume) of $80 \%$ ethanol. The vials containing the samples and vials of normal solutions $(80 \%$ ethanol to be used for calibration) were sealed with polyethylene caps and stored for I4 months. This method was designed to provide uniform samples for analysis. With a Bausch \& Lomb Spectronic 20 spectrophotometer measurements were made at $5 \mathrm{~nm}$ intervals between 380 and $650 \mathrm{~nm}$.

The solutions were used without purification or dilution, except where noted. Although the color of the solution was probably due 

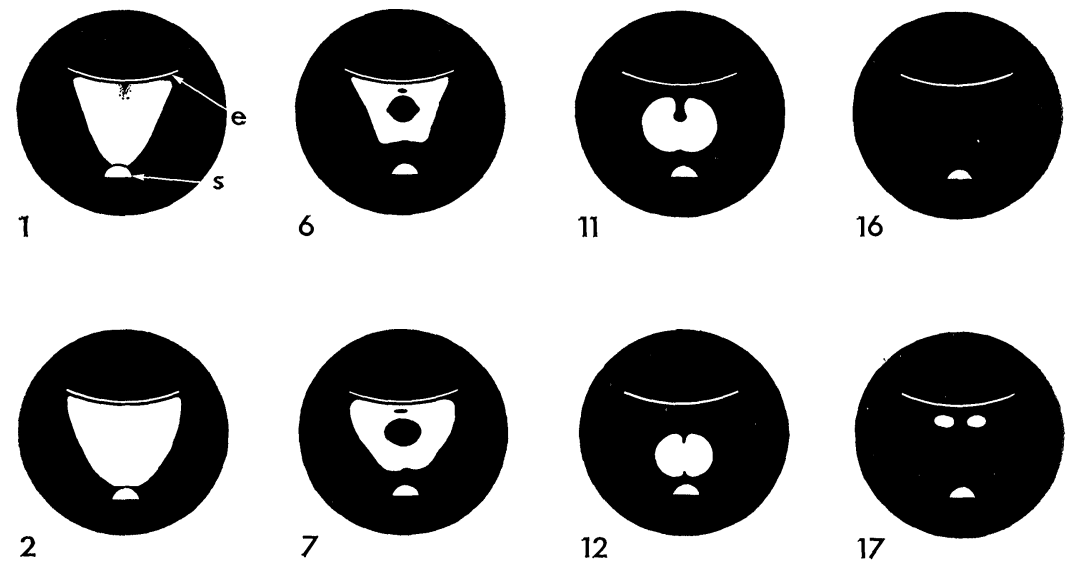

12
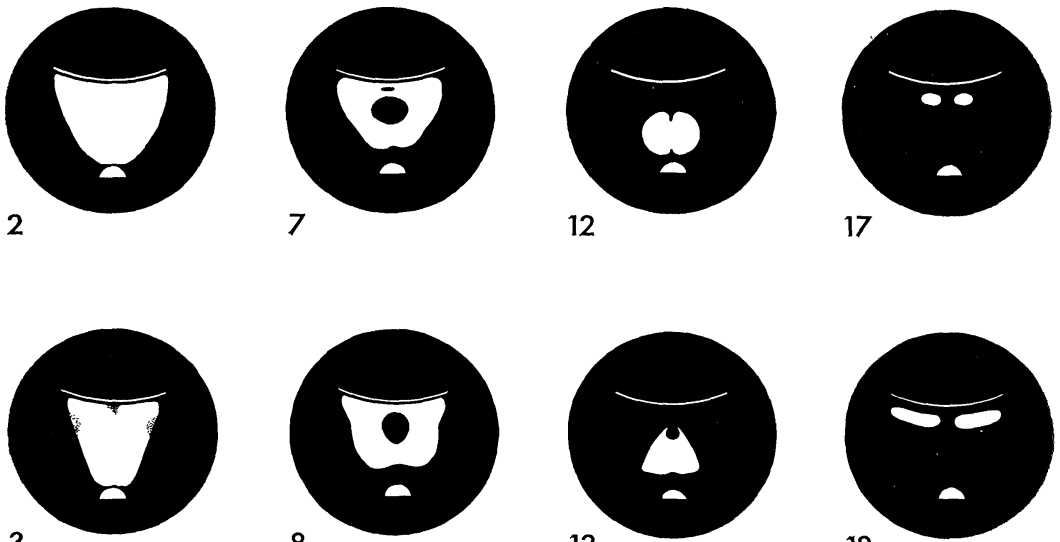

13
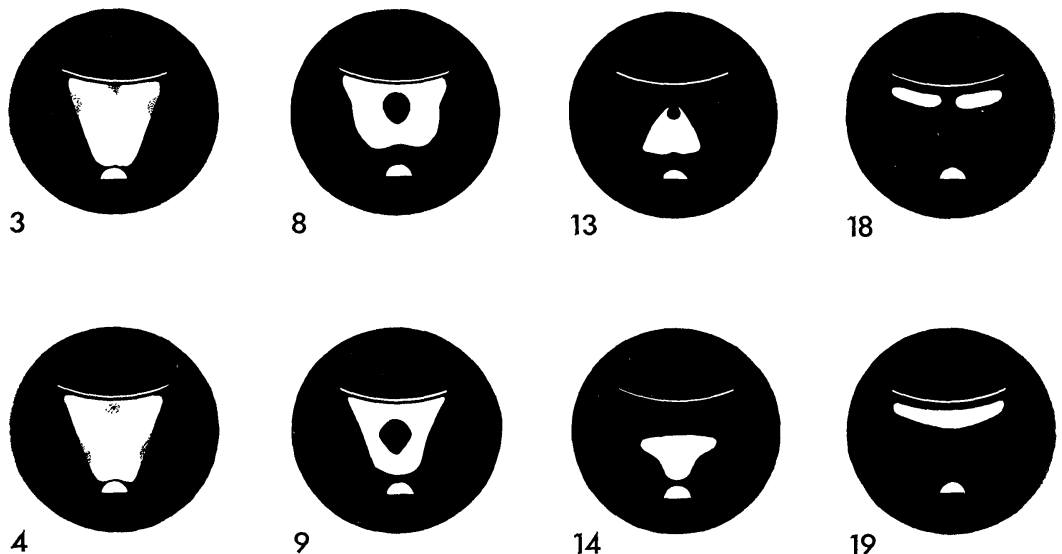

14
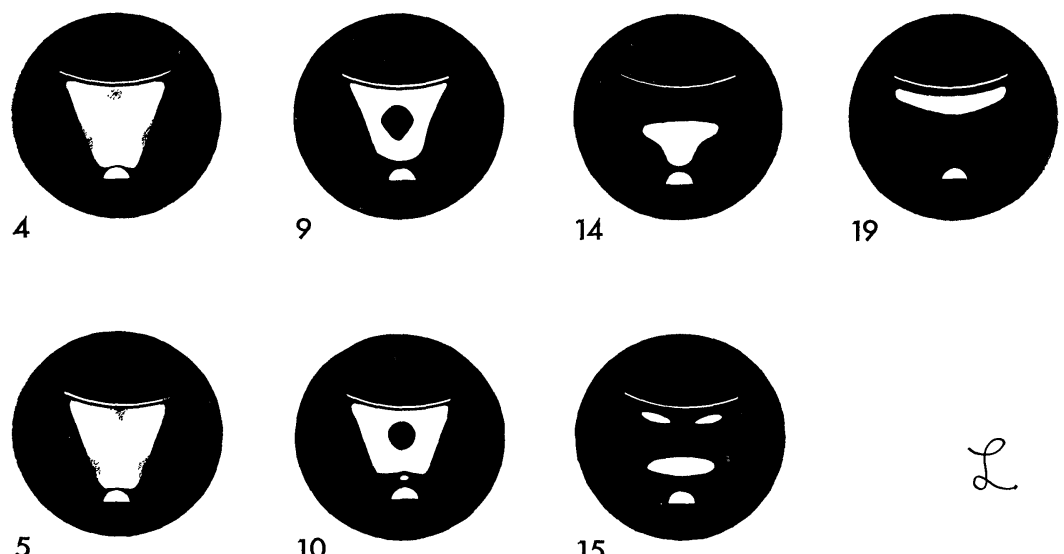

$\mathcal{L}$

15

Pinter - Latrodectus 
to non-melanin pigments, no attempt was made to identify the pigments. They are assumed to be ommochromes.

With the use of an ocular micrometer, accurate to $0.1 \mathrm{~mm}$, measurements were made of 34 morphological features. These measurements were selected because the margins of the structures were readily determined, thus permitting precise measurements which can be duplicated. The measurements taken between the eyes were not used because there were no significant differences between the individual species. Some ratios obtained from the remaining values are illustrated (Fig. 25) and discussed.

Using the dissecting techniques described by Levi (1965), I removed the epigyna from the specimens and exposed the internal genitalia by removing associated tissue and clearing the ducts in clove oil. Illustrations were made of the seminal receptacle, and the external and internal duct spirals (according to de Biasi, I962).

\section{RESULTS}

Abdominal markings. A variety of ventral markings are shown in Figures I-I9.

The vertical columns of venter patterns illustrate some of those observed in each of the populations.

In population No. I, the yellow pattern had a shield-like appearance. There were two specimens with complete shields which filled the ventral area (Fig. 2) and a few specimens had shields with indentations along the anterior or lateral margin (Figs. 3, 4 \& 5), but the majority of the shields had only a faint black indentation along the anterior border (Fig. I). With no exception among 83 specimens, the shield extended from the margin of the epigastric furrow to the base of the spinnerets; whereas, there were no examples of this feature among the specimens from the other three populations.

In population No. 2 a slightly different pattern emerged. Whereas the pattern did not extend posteriorly to the spinnerets, the entire anterior margin of the square was in contiguity at the epigastric furrow on all (136) specimens. Figures 6 through ro show five variations of the basic square pattern; a majority of the patterns were similar to that shown in fig. 8. In studying a much larger

EXPLANATION OF PLATE 36

Figs. 1-19. Abdominal Markings. Diagrammatic illustrations showing the ventral abdominal patterns, including the epigastric furrow (e) and spinnerets $(\mathrm{s})$; booklungs, epigyna, and lateral extensions of the dorsal pattern are not shown. 1-5. Latrodectus No. 1. 6-10. Latrodectus No. 2. 11-15. Latrodectus No. 3. 16-19. Latrodectus No. 4. 
sample, Abalos and Baez also observed this fact because they noted that the red irregular square stretched ". . almost to the spinnerets". A more conspicuous feature was the presence of a circular black spot in the center of the square. The presence of a round black spot, centered in a reddish yellow irregular square, was sufficient to distinguish specimens of population No. 2 from all other specimens.

Any attempt to characterize the faded yellow patterns observed in populations Nos. 3 and 4 becomes hazardous. No two patterns were alike in either of the two populations. The majority of the specimens from No. 3 had patterns similar to those illustrated in Figures I I and 12. The pattern edges were less distinct than those seen in Nos. I and 2. It is interesting to note that when McCrone and Levi ( 1966, p. 182) state ". . . the use of color pattern as a diagnostic species character must be done with great caution", they were probably studying the Peruvian counterpart of population No. 3. This variability is equally true of population No. 4, of which only four specimens were available for study. All four patterns are illustrated (Fig. I6 through 19). More specimens need to be studied before one can be reasonably certain that the yellow markings were restricted to the anterior portion of the venter.

Color. The pattern colors of Nos. I, 3 and 4 varied from dull to brilliant yellow, while those of No. 2 varied from dark red to reddish-yellow. But the colors of the preservatives were of more interest to me than the colors of the patterns. It was obvious that the preservative for No. 2 was tinted with a red pigment and the preservatives for Nos. I, 3 and 4 were colorless. Using the technique described earlier, the absorption curves of the preservatives of Nos. I, 2 and 3 were measured and plotted and a comparison of the curves in Figure 20 shows the dramatic difference between the undiluted samples (see unbroken curve in Fig. 2O). Following a 4:I dilution of the solution from population No. 2 (lowest curve), the spectral curve (dotted line) moved into the absorption range of the other samples. Undoubtedly, the same pigments are present in all three populations. In comparison with No. 3, one might suggest that the greater amount of dissolved pigments in No. 2 resulted from the larger pattern in No. 2. But it might be possible that the red and yellow pigments (non-melanins) are not necessarily limited to the pattern areas and are present in the black (melanin) pigmented areas as well. This argument becomes less important when comparing No. I to No. 2. Indeed, the area covered by the shield (No. I) is greater than that of the square (No. 2). Therefore, the greater in- 
tensity of red pigments in the preserving solution probably resulted from a greater abundance of soluble pigments in the ventral abdominal integument of No. 2 than in Nos. I or 3.

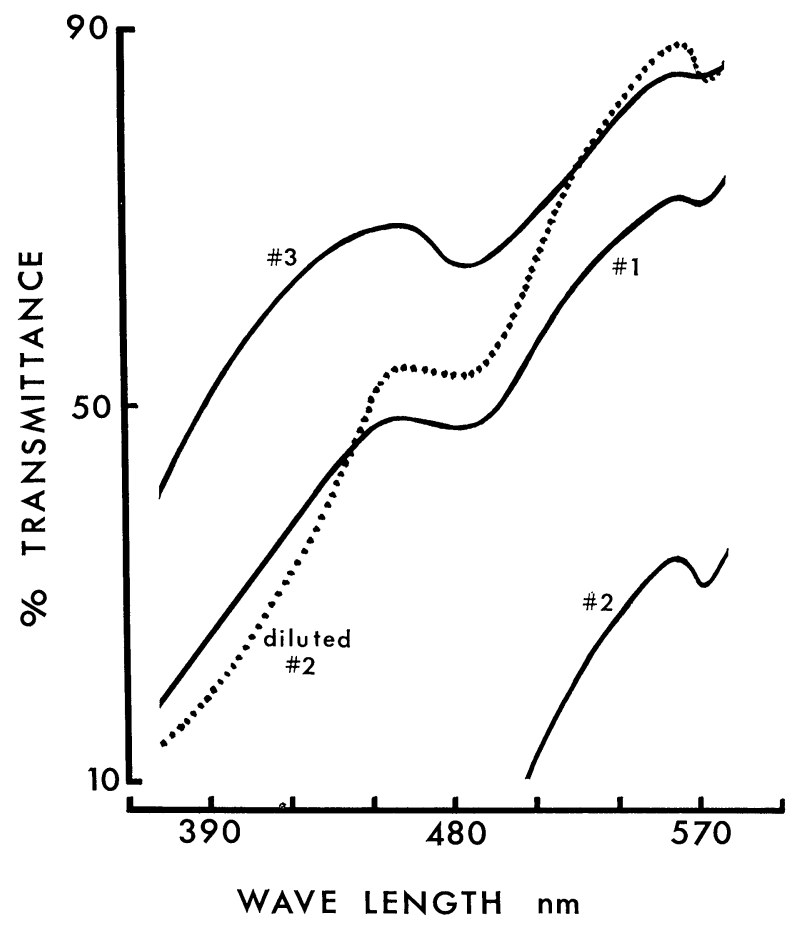

Fig. 20. Color. Spectral curves of pigments of Latrodectus Nos. 1, 2 and 3.

Internal Genitalia. The importance of studying the internal variations of the female genitalia of theridiids has been repeatedly stressed by Levi (1959, 1962 \& 1965). The basic structural difference in the number of coils of the duct is illustrated in Figures 2I through 24. No. I can easily be distinguished on the basis of one and a half to two turns of the duct. Figure 2 I illustrates a duct with one and three-quarter turns. This compares with that of No. I of Abalos and Baez (p. 63). In the other populations the ducts are more complex. In Nos. 2, 3 and 4 the ducts make approximately three complete turns. In the four specimens of No. 4 the ducts make an additional quarter turn. One might best describe this situation as three and one- 


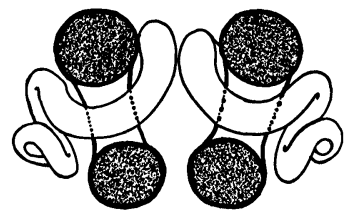

21

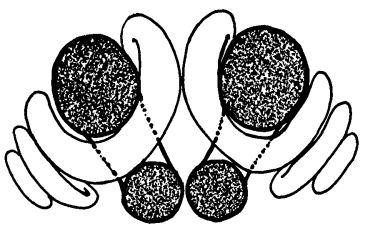

23

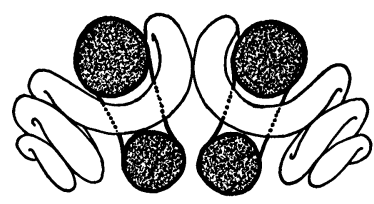

22

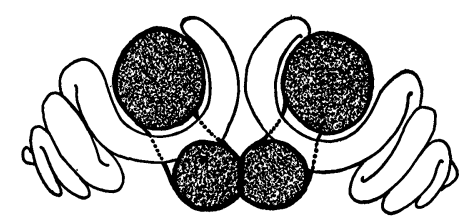

24

Figs. 21-24. Internal genitalia. Cleared dorsal view of epigyna. 21. Latrodectus No. 1. 22. Latrodectus No. 2. 23. Latrodectus No. 3. 24. Latrodectus No. 4. All figures are drawn to the same magnification.

quarter turns. Although No. 4 appears to have the most convoluted duct system, it would be necessary to examine more specimens before I could suggest that the quarter turn is signficant. Unfortunately, Abalos and Baez limited their characterization of the internal genitalia of Nos. 2, 3 and 4 to a single illustration (p. 63) which represents the duct system found in all three populations.

Measurements. A series of 34 measurements were made on a variety of external parameters on 94 specimens (30 specimens from populations Nos. I, 2, and 3; and four specimens from No. 4). After an analysis of all the values for each of the populations, the measurements from some parameters were discarded because they failed to yield normal distributions, e.g., values for the epigynal width yielded a bimodal distribution for population No. 3. Values for the sternum width produced a distribution which closely approximated a normal curve. Two ratios were made with the values of the sternum width and two other measurements which were selected at random from the list of remaining measurements. A third ratio was made by pairing the values of two parameters selected at random. Modified DiceLeraas diagrams for the ratios (FemurI/Sternum width, Metatar- 

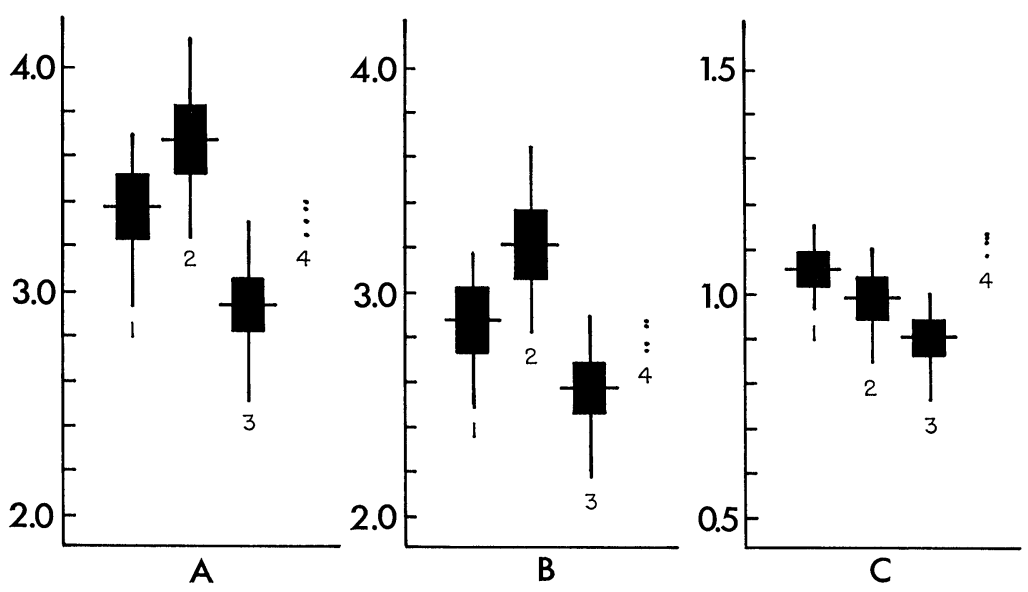

Fig. 25. Measurements. Ratios of Latrodectus Nos. 1, 2, 3, and 4. Modified Dice-Leraas diagrams of the ratios of Femur I/Sternum width (A), Metatarsus IV/Sternum width (B), and Femur I/Patella-tibia I. The horizontal line denotes the mean, the rectangle indicates the 95 per cent confidence intervals for the mean, and the vertical line represents the observed range. $\mathrm{N}$ equals 30 for Latrodectus Nos. 1, 2 and 3; $\mathrm{N}$ equals 4 for Latrodectus No. 4.

sus IV/Sternum width, and Femur I/Patella-tibia I) and the individual ratios for the four specimens from population No. 4 are illustrated in Figure 25.

The t-test was applied to the differences between the means of each of the ratios for each of the three populations. With a comparison of any of the three ratios, one finds a statistically significant difference (.95 confidence) between populations No. I and No. 2, No. I and No. 3, and No. 2 and No. 3.

\section{CONCLUSION}

By failing to consider geographic variation, Gerschman de Pikelin and Schiapelli confused a number of species. Their conclusion may be rejected on the grounds that there is reasonable evidence to conclude that at least three, and probably four, species besides $L$. geometricus are present in Santiago del Estero, Argentina. Because this study was limited to sympatric species, it was possible to show that a morphological discontinuity exists between the populations, hence reproductive isolation. These results support the findings of Abalos and Baez. 
Because more work needs to be done on individual, as well as geographical, variation of the several species of South American Latrodectus, no attempt was made at this time to determine the names of species Nos. I, 2, 3, and 4 from Santiago del Estero, Argentina.

Abalos, J. W.

\section{Literature Cited}

1962. The egg sac in the identification of species of Latrodectus. Psyche 69: 268-270.

Abalos, J. W. and E. C. Baez.

1967. The spider genus Latrodectus in Santiago del Estero, Argentina. Animal Toxins, Pergamon Press, Oxford. pp. 59-74.

DeBiasi, P.

1962. Estrutra interna e presenca de segmentos de embolo no epigino de Latrodectus geometricus. Papeis Avulsos, Sào Paulo 15: 327-331.

Gerschman de Pikelin, B. S. \& D. E. Schiapelli.

1965. El genero Latrodectus Walckenaer, 1805, en La Argentina. Rev. Soc. Entomol. Argentina 27: 51-59.

LeVI, H. W.

1959. The spider genus Latrodectus. Trans. Amer. Micros. Soc. 78: 7-43.

1965. Techniques for the study of spider genitalia. Psyche 72:152-158.

Levi, H. W. \& L. R. Levi.

1962. The genera of the spider family Theridiidae. Bull. Mus. Comp. Zool. $127(1): 1-71$.

McCrone, J. D. \& H. W. Levi.

1964. North American Widow spiders of the Latrodectus curacaviensis group. Psyche 71: 12-27.

1966. Postembryological development of spiderlings from two Peruvian Latrodectus populations. Psyche 69: 268-270. 

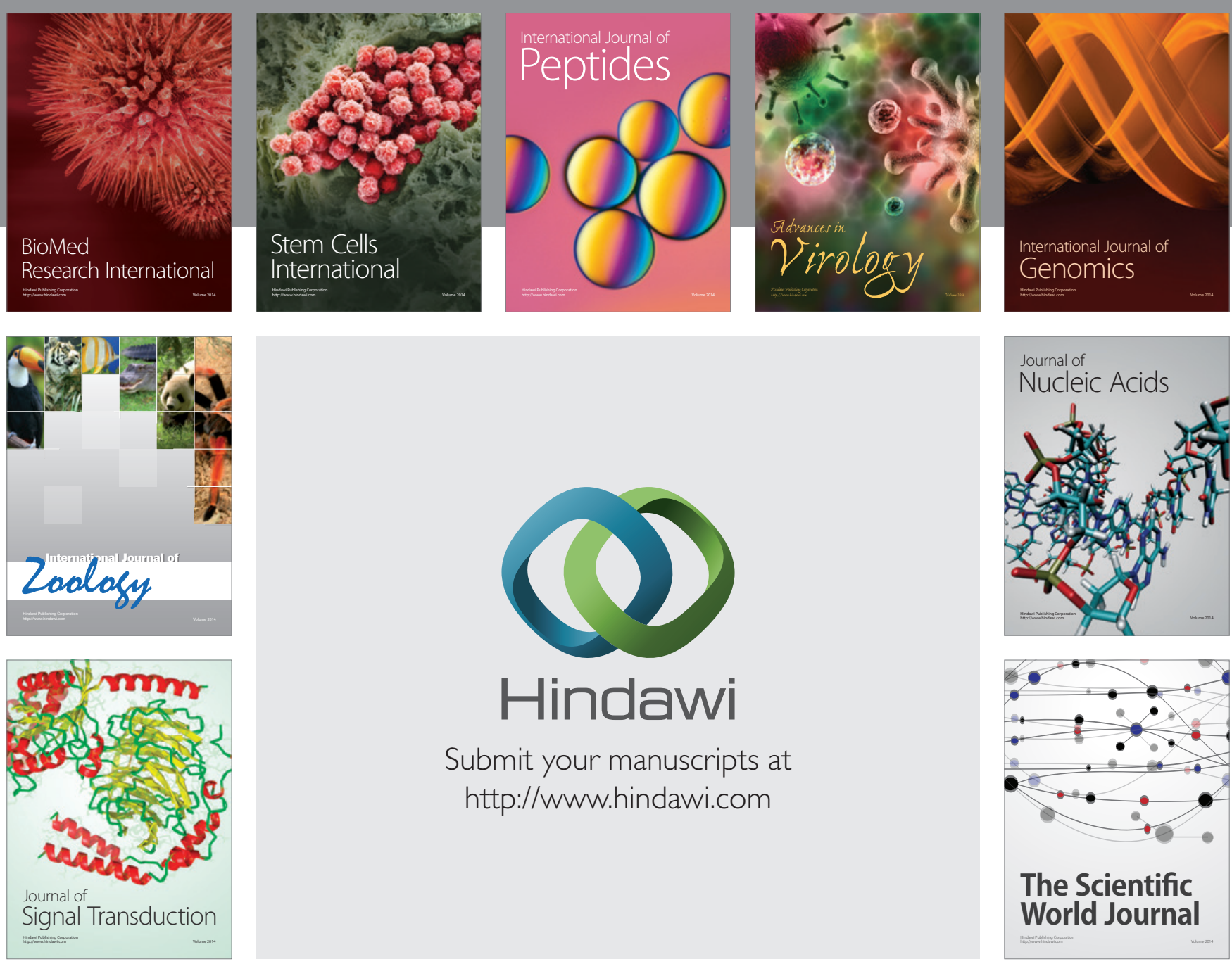

Submit your manuscripts at

http://www.hindawi.com
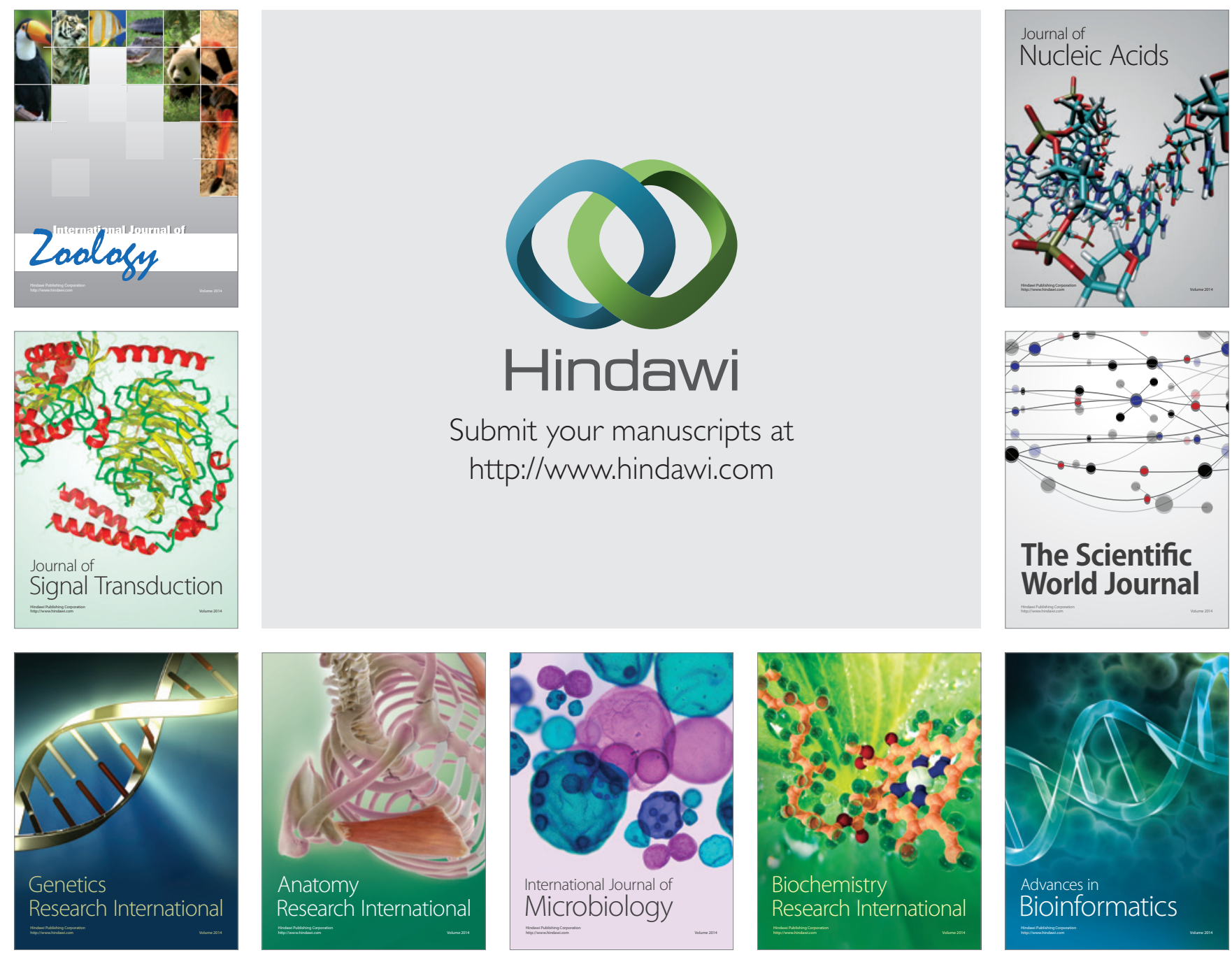

The Scientific World Journal
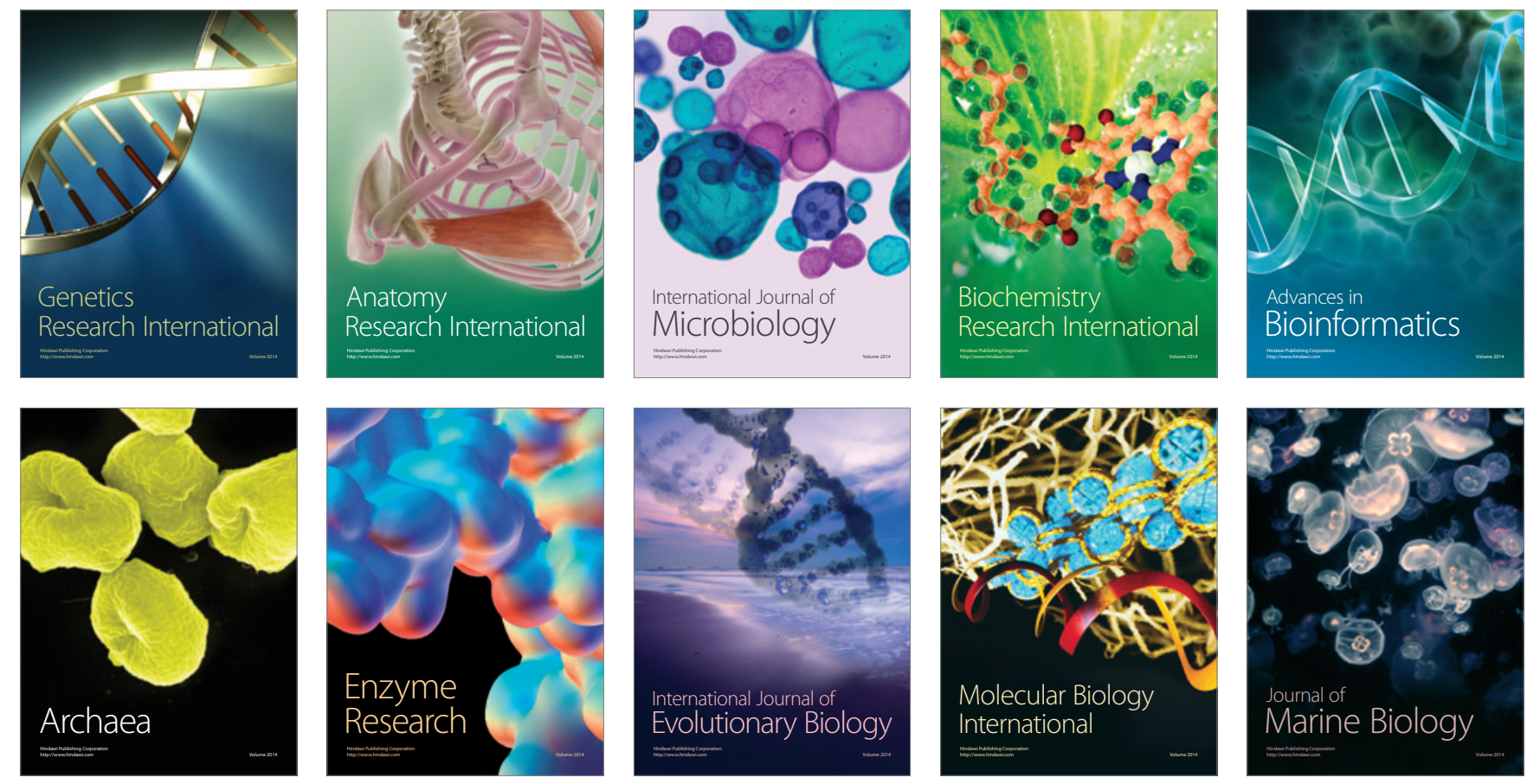